\title{
Does supplemental photodynamic therapy optimize the disinfection of bacteria and endotoxins in one-visit and two-visit root canal therapy? A randomized clinical trial
}

\author{
Diego G.D. Rabello ${ }^{a}$, Bruna J.M. Corazza ${ }^{a}$, Luciana L. Ferreira ${ }^{a}$, Mauro P. Santamaria ${ }^{a}$, \\ Ana P.M. Gomes ${ }^{\mathrm{a}}$, Frederico C. Martinho ${ }^{\mathrm{a}, \mathrm{b}, *}$
}

a Department of Restorative Dentistry, Endodontic Division, São José dos Campos Dental School, State University of São Paulo, UNESP, Brazil

b University of Maryland-Baltimore, Department Oral Sciences \& Therapeutics, School of Dentistry, Baltimore, Maryland 21201

\section{A R T I C L E I N F O}

\section{Keywords:}

Bacteria

Root Canal

Disinfection

Endotoxins

Endodontics

Photodynamic Therapy

\begin{abstract}
A B S T R A C T
Aim: To evaluate the effectiveness of supplemental photodynamic therapy (PDT) in optimizing the removal of bacteria and endotoxins from primarily infected root canals after one-visit and two-visit treatments.

Methodology: Twenty-four primarily infected root canals with apical periodontitis were selected and randomly divided into one-visit $(n=12)$ and two-visit treatment groups $(n=12)$. Chemo-mechanical preparation (CMP) was performed by using the single-file reciprocating technique $+2.5 \% \mathrm{NaOCL}$ and a final rinse with $17 \%$ EDTA. The photosensitizer agent (methylene blue $0.1 \mathrm{mg} / \mathrm{mL}$ ) was applied to root canals for $60 \mathrm{~s}$ before application of laser with a potency of $60 \mathrm{~mW}$ and energy density of $129 \mathrm{~J} / \mathrm{cm}^{2}$ for $120 \mathrm{~s}$ after CMP in the one-visit treatment and after 14-day inter-appointment medication with $\mathrm{Ca}(\mathrm{OH})_{2}+$ Saline solution (SSL) in the two-visit treatment. Samples were collected before and after root canal procedures. Endotoxins were quantified by chromogenic limulus amebocyte lysate assay. Culture techniques were used to determine bacterial colony-forming unit counts.

Results: Bacteria and endotoxins were detected in $100 \%$ of the initial samples, with median values of $1.97 \times 10^{5}$ $\mathrm{CFU} / \mathrm{mL}$ and $24.983 \mathrm{EU} / \mathrm{mL}$, respectively. The CMP using single-file reciprocating technique was effective in the reduction of bacteria and endotoxins (All, $\mathrm{p}<0.05$ ). The supplemental PDT was effective in reducing bacterial load in the one-visit $\left(\mathrm{p}<0.05\right.$ ) but not in the two-visit treatment after use of $\mathrm{Ca}(\mathrm{OH})_{2}$ medication for 14 days ( $\mathrm{p}>0.05$ ). In the two-visit group, after 14 days of inter-appointment medication with $\mathrm{Ca}(\mathrm{OH})_{2}$, a significant reduction in the median levels of endotoxins was found in comparison to CMP alone (from 1.041 to 0.094 EU/ $\mathrm{mL})(\mathrm{p}<0.05)$. Despite the type of treatment, the supplemental PDT was not effective against endotoxins (p > 0.05).

Conclusions: The photodynamic therapy optimized the disinfection of bacteria from root canals in one-visit but not for two visit treatment modality with the accomplishment of calcium hydroxide medication. Despite the type of treatment, the supplemental PDT was not effective against endotoxins.
\end{abstract}

\section{Introduction}

It has long been known that an effective disinfection of the root canal systems has not only to do with elimination of bacteria, removal of dead cells and dissolving of pulp tissue [1,2], but also with debridement and eradication of biofilms [3] as well as elimination and neutralization of bacterial virulence factors [4-6].

The knowledge of the microbial ecology involved in the infection is a key step for determining an optimal disinfection protocol [7]. It is known that primary endodontic infection is polymicrobial, comprising both Gram-positive and Gram-negative bacterial species [7,8]. Lipopolysaccharide (LPS, also known as endotoxin) is the main virulence factor found in the outer membrane of the bacterial cell [9], exhibiting high biological activity [10]. Endotoxin has been detected in $100 \%$ of the primarily infected teeth $[8,11]$, with higher levels of LPS being correlated with development of symptoms and severity of bone destruction [11-15].

Despite the advances in instrumentation techniques with the use of

\footnotetext{
* Corresponding author at: São José dos Campos Dental School, State University of São Paulo, UNESP, Department of Restorative Dentistry, Endodontic Division, Eng Francisco José Longo, 777, São José dos Campos, São Paulo, CEP 12245-000, Brazil.

E-mail addresses: martinhof@hotmail.com, fmartinho@umaryland.edu, Frederico.martinho@fosjc.unesp.br (F.C. Martinho).
} 
reciprocating single-instrument $[5,8,16]$ or multiple NiTi files systems in continuous rotation motion [11,16], studies preconizing one- and two-visit treatment approach have failed in demonstrating an optimal disinfection of the root canal system $[5,6,8,17,18]$.

In the search of supplemental methods to optimize the root canal disinfection, photodynamic therapy (PDT) has been considered in the past years [19-24]. However, few clinical studies evaluated the effectiveness of PDT in the disinfection of the root canal systems [19-21]. Moreover, up to now, there is no clinical study evaluating the effectiveness of PDT in reducing and/or eliminating endotoxins from primarily infected root canals. To address, this study evaluated the effectiveness of supplemental photodynamic therapy (PDT) in optimizing the removal of bacteria and endotoxins from primarily infected root canals after one-visit and two-visit treatments.

\section{Material and methods}

This study was designed as a randomized clinical trial, which was registered and approved by the institutional Review Board (protocol \# NCT02824601). The local human research ethics committee approved the protocol describing the sample collection for this investigation, with all the patients being volunteers and signing an informed consent form. Sample size calculation: the minimum sample size was determined to be 12 teeth per group on the basis of a $10 \%$ mean difference in outcome between the groups and power $=0.80(\mathrm{P}<0.05)$. Randomization, allocation, concealment and blinding: An external person generated a random allocation sequence in a computer program. This sequence was placed in opaque, sealed envelopes. Each envelope included the randomization code for each patient, which was only revealed during the treatment procedure, just after the chemo-mechanical preparation. It was ensured that both the patient and the operator were unaware of the treatment protocol assigned until completion of chemo-mechanical preparation. After, the blinding of the examiners was not practical because the application of PDT after chemo-mechanical preparation (CMP) in the 1-visit group or the placement of $\mathrm{Ca}(\mathrm{OH})_{2}$ medication in the 2-visit group.

\subsection{Patient selection}

Twenty-four patients attending the Dental School of the São Paulo State University (UNESP), São José dos Campos, Brazil, for primary endodontic treatment were included in the present study. The demographic data from the patients that participated in this study is shown is Table 1. A detailed dental and general health history was obtained from each patient. Those who had received antibiotic treatment during the past three months were excluded. All the teeth were single rooted with primary endodontic infection showing apical periodontitis, intact pulp chamber walls, presence of 1 root canal, and absence of periodontal pockets deeper than $4 \mathrm{~mm}$ as well as root canal calcification. The diagnosis of pulpal necrosis was confirmed by a negative response to the cold test. The teeth that could not be isolated with rubber dam were also excluded.

\subsection{Sampling/treatment procedures}

Files, instruments, and all the materials used in this study were treated with $\mathrm{Co}^{60}$ gamma radiation ( $20 \mathrm{kGy}$ for $6 \mathrm{~h}$ ) for sterilization and

Table 1

Demographic data of the study.

\begin{tabular}{lll}
\hline Group & Male/female & Age (years) \\
\hline 1-visit-treatment & $7 / 5$ & $48 \pm 15.49$ \\
2-visit-treatment & $8 / 4$ & $38.6 \pm 13.97$ \\
Total & $15 / 9$ & $40.3 \pm 14.36$ \\
\hline
\end{tabular}

elimination of pre-existing endotoxins (EMBRARAD; Empresa Brasileira de Radiação, Cotia, SP, Brazil). The method used for disinfection of the operative field had been previously described elsewhere [8]. Briefly, the teeth were isolated with rubber dam. The crown and surrounding structures were disinfected with $30 \% \mathrm{H}_{2} \mathrm{O}_{2}$ (volume/volume [V/V]) for $30 \mathrm{~s}$, followed by $2.5 \% \mathrm{NaOCl}$ for the same period of time and then inactivated with $5 \%$ sodium thiosulfate. The sterility of the external surfaces of the crown was checked by taking a swab sample from the crown surface and streaking it onto blood agar plates, which were then incubated both aerobically and anaerobically.

A two-stage access cavity preparation was made without the use of water spray, but under manual irrigation with sterile/apyrogenic saline solution (Accosol, AccoScience, Sorocaba, Brazil) and by using sterile/ apyrogenic high-speed diamond bur. The first stage was performed for a major removal of contaminants, including carious lesion and restoration. In the second stage, before entering the pulp chamber, the access cavity was disinfected according to the protocol described above. Sterility and apirogenic condition of the internal surface of the access cavity was checked as previously described and all procedures were performed aseptically.

For endotoxin samples, a sterile/apyrogenic paper points (size \#15, Dentsply-Maillefer, Balaigues, Switzerland) was introduced into the full length of the canal, which was determined radiographically, and retained in position during $60 \mathrm{~s}$ for sampling ${ }^{8}$. Immediately after, the sample was placed in pyrogen-free glass and immediately suspended in $1 \mathrm{~mL}$ of limulus amebocyte lysate (LAL) water (Lonza, Walkersville, MD, USA) and frozen at $-80^{\circ} \mathrm{C}$ for further study of endotoxins by using kinetic chromogenic limulus amebocyte lysate (LAL) assay (Lonza, Walkersville, MD, USA). For bacterial samples, this sampling procedure was repeated with 3 paper points, which were then pooled in a sterile tube containing $1 \mathrm{~mL}$ of viability medium Göteborg agar III (VMGA III).

\subsection{Study design}

For the one-visit group, root canal samplings were performed at the baseline, immediately after chemo-mechanical preparation, and after PDT; for the two-visit group, root canal samplings were performed at the baseline, immediately after chemo-mechanical preparation, after 14-days of intracanal medication, and after PDT.

Next, the root canal length was determined with preoperative radiograph and confirmed by using an apex locator (RomiApex A-15; Romidan Dental Solution, Kiryat-Ono, Israel). When the anatomy allowed the passive entrance of K-file (VDW, München, Germany) \#30 to the working length (WL), teeth were instrumented with the R50 Reciproc file (VDW, München, Germany). If K-file \#20 was the one that fitted in the canal, than it was used the R40 Reciproc file. When the Kfile \#20 was not able to get to the WL passively, than Reciproc R25 was used instead. Instrument, which was used in reciprocating motion powered by a torque-limited electric motor (VDW Gold, VDW) with preset adjustments. The instrument was used in an in-and-out pecking motion of about $3 \mathrm{~mm}$ in amplitude with apical pressure. After three pecking motions, the instrument was removed from the canal, which was irrigated with $2.5 \% \mathrm{NaOCl}$ [8]. Next, a \#15 K-type file (Dentsply, Maillefer, Balaigues, Switzerland) was inserted at the working length (WL) to check whether the canal was patent. These procedures were repeated until the Reciproc instrument reached the WL. Irrigation throughout the procedures was performed by using disposable syringe and 30-G NaviTip needle (Ultradent, South Jordan, UT, USA). Each root canal was instrumented with a single Reciproc instrument, and each instrument was used to prepare only one canal. Before the second sampling after CMP, the root canals were irrigated with 17\% EDTA for $3 \mathrm{~min}$, followed by $5 \mathrm{~mL}$ of $2.5 \% \mathrm{NaOCl}$ solution, which was inactivated with $5 \mathrm{~mL}$ of sterile $0.5 \%$ sodium thiosulfate during 1 min before being removed with $5 \mathrm{~mL}$ of LAL water.

After CMP, In the one-visit group, the root canal was washed thoroughly with sterile/apyrogenic saline solution and dried with 
sterile/apyrogenic paper points (Dentsply, Maillefer, Balaigues, Switzerland). Next, the photosensitizer methylene blue $(0.1 \mathrm{mg} / \mathrm{mL})$ (São Carlos, São Paulo, Brazil) was placed into the root canal $(0.5 \mathrm{~mL})$ by using an endodontic micro needle until a complete fill has been achieved and then agitated inside the root canal by using a \#25 K-type file (Dentsply, Maillefer) to ensure that methylene blue reached the full extension of the root canal. The photosensitizer agent (methylene blue $0.1 \mathrm{mg} / \mathrm{mL}$ ) was applied to root canals for $60 \mathrm{~s}$ before application of laser with energy density of $129 \mathrm{~J} / \mathrm{cm}^{2}$ for $120 \mathrm{~s}$ after CMP. The illumination was performed with a $300-\mu \mathrm{m}$ diameter fiber coupled with a diode laser (MMOptics, São Carlos, SP, Brazil). The fiber was placed in the apical portion of the root canal at a point where resistance to the fiber could be felt with spiral movements (from apically to cervically) manually performed to ensure full diffusion of light inside the canal lumen $[20,21]$. These movements were repeated 10 times per minute $[20,21]$. The laser emitted a $660-\mathrm{nm}$ light at a total power of $60 \mathrm{~mW}$ for 120 s. Next, a new bacteria and endotoxin samples were performed as previously described. In order to remove methylene blue from root canals a final rinse with $10 \mathrm{~mL}$ of $2.5 \% \mathrm{NaOCl}$ solution was performed.

Particularly, in the two-visit group, after CMP, the root canal was filled with freshly prepared paste of $\mathrm{Ca}(\mathrm{OH})_{2}$ in saline solution for a period of 14 days. $\mathrm{Ca}(\mathrm{OH})_{2}$ paste was inserted into the root canals with the aid of a lentulo spiral filler (Dentsply, Maillefer). Care was taken to properly fill the root canal with $\mathrm{Ca}(\mathrm{OH})_{2}$ paste. The paste was plugged at the canal orifice level by using a sterile cotton pellet. Next, the access cavity was properly closed with ionomer cement. After 14 days of intracanal medication, the tooth was isolated and disinfected and the provisional restoration was removed. Next, the root canals were irrigated with $10 \mathrm{~mL}$ of LAL water, and calcium hydroxide medication was neutralized with $0.5 \%$ citric acid (Sigma-Aldrich, St. Louis, Missouri, USA). Afterwards, the root canals were irrigated with $10 \mathrm{~mL}$ of LAL water and dried with sterile/apyrogenic paper points, and PDT was performed as previously described. In order to remove methylene blue from root canals a final rinse with $10 \mathrm{~mL}$ of $2.5 \% \mathrm{NaOCl}$ solution was performed.

\subsubsection{Quantification of total cultivable bacterial counts}

In the present study, the method used for culture procedures was previously reported by the author elsewhere [8]. Briefly, the transport media containing the root canal samples were thoroughly shaken for 60 s (Vortex; Marconi, Piracicaba, São Paulo, Brazil). Serial 10-fold dilutions were made up to $10^{-4}$ in tubes containing fastidious anaerobe broth (FAB; Lab M, Bury, UK). Fifty microliters of the serial dilutions was plated onto $5 \%$ defibrinated sheep blood fastidious anaerobe agar (FAA; LabM) by using sterile plastic spreaders to culture non-selectively obligate anaerobes and facultative anaerobes. The plates were incubated at $37^{\circ} \mathrm{C}$ in anaerobic atmosphere for up to 14 days. After this period, colony-forming units (CFUs) were visually quantified for each plate.

\subsubsection{Quantification of endotoxin concentration}

The kinetic chromogenic LAL assay (Lonza; São Paulo, São Paulo, Brazil) was used for quantification of endotoxins, with Escherichia coli endotoxin being used as standard. A positive control (root canal sample contaminated with a known amount of endotoxin) was included for each sample to determine the presence or absence of interfering agents. For the test, $100 \mathrm{~mL}$ of apyrogenic water (reaction blank), five standard endotoxin solutions (0.005-50 endotoxin units in $\mathrm{EU} / \mathrm{mL}$ ), root canal samples, and positive controls (root canal samples contaminated with a known concentration of endotoxin, i.e. $10 \mathrm{EU} / \mathrm{mL}$ ) were added to a 96well apyrogenic plate. The tests were carried out in quadruplicate. The plate was incubated at $37^{\circ} \mathrm{C} \pm 1{ }^{\circ} \mathrm{C}$ for $10 \mathrm{~min}$ in a Kinetic-QCL (Lonza) reader, which was coupled to a microcomputer by means of the WinKQCL software. Next, $100 \mathrm{~mL}$ of chromogenic reagent was added to each well. After the beginning of the kinetic test, the software continuously monitored absorbance at $405 \mathrm{~nm}$ in each microplate well and automatically calculated the $\log / \log$ linear correlation between reaction time of each standard solution and corresponding endotoxin concentration.

\subsection{Statistical analysis}

The data collected (CFUs and endotoxin concentrations) were statistically analysed by using the SPSS for Windows (SPSS Inc., Inc, Chicago, IL, USA). The sample size calculation revealed that 12 teeth per group would suffice to show a $5 \%$ difference in bacterial counts with a power of $80 \%$. Repeated measure ANOVA and Tukey's tests were used to for intragroup analysis. One-Way ANOVA and Tukey's test was used for intergroup analysis. The significance level was always set at $5 \%$ $(\mathrm{P}<0.05)$.

\section{Results}

A total of 24 patients, being 15 males and 9 females, participated in this study. Random allocation of subjects resulted in 12 patients in the 1 -visit-treatment group ( 7 males and 5 females) and 12 patients in the 2 -visit-treatment group ( 8 males and 4 females) (Table 1 ). The mean age of patients in 1-visit-treatment group was $48 \pm 15.49$ whilst it was $38.6 \pm 13.97$ in the two-visit-treatment group (Table 1). Recruitment was performed from February/2015 until June/2016. The trial was completed in June/2016. Fig. 1 shows the participant flow chart.

\subsection{Effect of PDT on bacterial counts}

Bacteria were found in all baseline samples of the 24 primarily infected root canals investigated, with total bacterial count ranging from $1.09 \times 10^{4}$ to $5.38 \times 10^{6} \mathrm{CFU} / \mathrm{mL}$ (median value, $1.97 \times 10^{5} \mathrm{CFU}$ / $\mathrm{mL}$ ). Individual, median and range values of bacterial counts found in the one-visit and two-visit groups for the baseline samples are shown in Table 2. The CMP using single-file reciprocating instrumentation and irrigation with $2.5 \% \mathrm{NaOCl}$ and $17 \%$ EDTA reduced the median value of total bacterial load in both one-visit (from $1.94 \times 10^{5}$ to $7.01 \times 10^{2} \mathrm{CFU} / \mathrm{mL}$ ) and two-visit groups (from $2.01 \times 10^{5}$ to $6.73 \times 10^{2} \mathrm{CFU} / \mathrm{mL}$ ) (all, $\mathrm{p}<0.05$ ) (Table 2). Intergroup comparison of total CFU counts found after CMP showed no difference between onevisit and two-visit groups ( $\mathrm{p}>0.05$ ). The median percentage values of bacterial reductions were $95.18 \%$ and $96.07 \%$ for one-visit and twovisit treatments, respectively (Table 2). After CMP, bacteria were still recovered from infected root canals in both one-visit (6/12) and twovisit $(7 / 12)$ groups. In the one-visit group, the supplemental PDT not only significantly decreased the level of bacteria (from $7.01 \times 10^{2}$ to $\left.1.16 \times 10^{2} \mathrm{CFU} / \mathrm{mL}\right)(\mathrm{p}<0.05)$, but also decreased the number of root canals yielding positive culture after CMP alone (6/12 after CMP; $3 / 12$ after PDT). The median percentage values of bacterial reductions increased from $95.18 \%$ to $98.70 \%$. After 14 days of inter-appointment medication with $\mathrm{Ca}(\mathrm{OH})_{2}$, a significant median reduction of bacterial load was found in the two-visit treatment after CMP alone (from $6.73 \times 10^{2}$ to $\left.1.22 \times 10^{2} \mathrm{CFU} / \mathrm{mL}\right)(\mathrm{p}<0.05)$ (Table 2). Thus, an increase in the median percentage value of bacterial reduction was observed (from $96.07 \%$ to $99.05 \%$ ). The supplemental PDT in the twovisit group showed no significant improvement in the reduction of bacterial load after use of $\mathrm{Ca}(\mathrm{OH})_{2}$ medication for 14 days $\left(1.19 \times 10^{2} \mathrm{CFU} / \mathrm{mL}\right)(\mathrm{p}>0.05)($ Table 2$)$.

\subsection{Effect of PDT on endotoxin}

The standard curve for detection of endotoxins fulfilled the criteria of linearity $(\mathrm{r}=1)$. With regard to the baseline samples, the LAL-assay indicated the presence of endotoxins in $100 \%$ of the root canal samples $(24 / 24)$, with a median value of $24.983 \mathrm{EU} / \mathrm{mL}$ (ranging from 7.490 to $67.100 \mathrm{EU} / \mathrm{mL}$ ). Individual median and range values of endotoxin levels found in the one-visit and two-visit groups for the baseline samples 


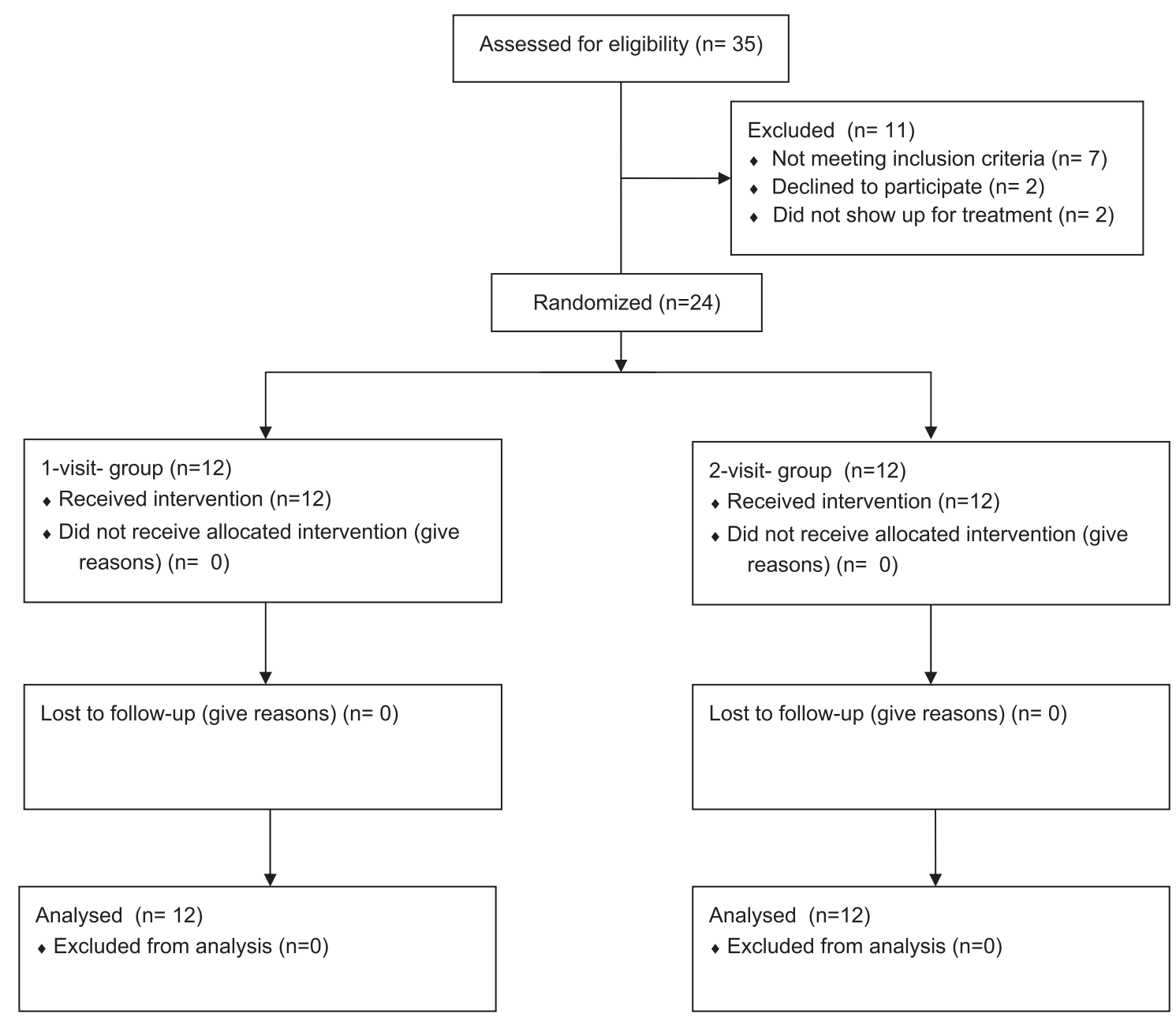

Fig. 1. Consolidated standards of reporting trials flow chart.

are shown in Table 3. With regard to the CMP, the use of reciprocating single-instrument and irrigation with $2.5 \% \mathrm{NaOCl}$ and $17 \%$ EDTA reduced the median levels of endotoxin in both one-visit (from 24.942 to $1.920 \mathrm{EU} / \mathrm{mL}$ ) and two-visit groups (from 25.067 to $1.041 \mathrm{EU} / \mathrm{mL}$ ) groups (all $\mathrm{p}<0.05$ ) (Table 3 ). The median percentage values of endotoxin reduction were $94.91 \%$ and $95.03 \%$ for one-visit and two-visit treatments, respectively (Table 3). After CMP, endotoxin was still recovered from $100 \%$ of the root canal samples (Table 3). Particularly, in the one-visit group, the supplemental PDT did not optimize the removal/elimination of endotoxins achieved with CMP alone as shown in Table 3, and endotoxins were still detected in 100\% (12/12) of the root canal samples. In the two-visit group, after 14 days of inter-appointment medication with $\mathrm{Ca}(\mathrm{OH})_{2}$, a significant reduction in the median levels of endotoxins was found in comparison to CMP alone (from 1.041 to $0.094 \mathrm{EU} / \mathrm{mL}$ ) ( $\mathrm{p}<0.05$ ) (Table 3), with only $4 / 12$ root canals being positive for endotoxins. Particularly, the supplemental PDT in the

Table 2

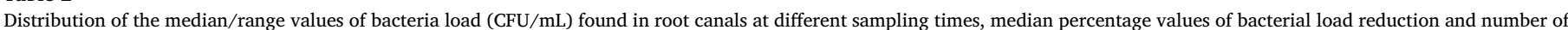
root canals with positive culture.

\begin{tabular}{|c|c|c|c|}
\hline \multicolumn{4}{|l|}{ 1-Visit Treatment } \\
\hline Samping times & Bacterial Load (CFU/mL) Median/Range values & Median $\%$ of reduction & \# of root canals with positive cultures \\
\hline Before chemomechanical preparation & $1.94 \times 105(1.09 \times 104-4.39 \times 106) \mathrm{Aa}$ & $\mathrm{x}$ & $12 / 12$ \\
\hline After chemomechanical preparation & $7.01 \times 102\left(0-3.45 \times 10^{3}\right) \mathrm{Bb}$ & $95.18 \%$ & $6 / 12$ \\
\hline After supplementary-PDT therapy & $1.16 \times 102(0-1.35 \times 102) \mathrm{Cc}$ & $98.70 \%$ & $3 / 12$ \\
\hline \multicolumn{4}{|l|}{ 2-Visit Treatment } \\
\hline Samping times & Bacterial Load (CFU/mL) Median/Range values & Median $\%$ of reduction & \# of root canals with positive cultures \\
\hline Before chemomechanical preparation & $2.01 \times 105(1.27 \times 104-5.38 \times 106) \mathrm{Aa}$ & $\mathrm{x}$ & $12 / 12$ \\
\hline After chemomechanical preparation & $6.73 \times 102(0-2.94 \times 103) \mathrm{Bb}$ & $96.07 \%$ & $7 / 12$ \\
\hline After $\mathrm{Ca}(\mathrm{OH}) 2$ interappointment medication & $1.22 \times 102(0-1.93 \times 102) \mathrm{Cc}$ & $99.05 \%$ & $3 / 12$ \\
\hline After supplementary-PDT therapy & $1.19 \times 102(0-1.47 \times 102) \mathrm{Cc}$ & $99.13 \%$ & $2 / 12$ \\
\hline
\end{tabular}

- Intra-group analysis - different capital letters $=p<0.05$.

- Inter-group analysis - different lower case letters $=p<0.05$. 
Table 3

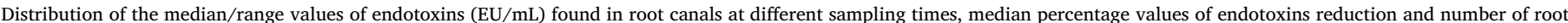
canals positive for endotoxins.

\begin{tabular}{|c|c|c|c|}
\hline Samping times & Endotoxin contents (EU/mL) Median/Range values & Median $\%$ of reduction & \# of root canals positive for endotoxins \\
\hline Before chemo-mechanical preparation & $24.941(8.293-67.100) \mathrm{Aa}$ & $\mathrm{x}$ & $12 / 12$ \\
\hline After chemo-mechanical preparation & $1.920(0.054-4.310) \mathrm{Bb}$ & $95.03 \%$ & $12 / 12$ \\
\hline After supplementary-PDT therapy & $0.718(0.184-3.479) \mathrm{Bb}$ & $96.11 \%$ & $12 / 12$ \\
\hline
\end{tabular}

\begin{tabular}{|c|c|c|c|}
\hline \multirow[b]{2}{*}{ Samping times } & \multicolumn{3}{|l|}{ 2-Visit Treatment } \\
\hline & Endotoxin contents (EU/mL) Median/Range values & Median $\%$ of reduction & \# of root canals positive for endotoxins \\
\hline Before chemo-mechanical preparation & 25.067 (7.490-43.095) Аа & $\mathrm{x}$ & $12 / 12$ \\
\hline After chemo-mechanical preparation & $1.041(0.083-3.910) \mathrm{Bb}$ & $94.91 \%$ & $12 / 12$ \\
\hline After $\mathrm{Ca}(\mathrm{OH}) 2$ medication & $0.094(0.03-0.147) \mathrm{Cc}$ & $98.01 \%$ & $4 / 12$ \\
\hline After supplementary-PDT therapy & $0.081(0.029-0.480) \mathrm{Cc}$ & $98.16 \%$ & $4 / 12$ \\
\hline
\end{tabular}

- Intra-group analysis - different capital letters $=\mathrm{p}<0.05$.

- Inter-group analysis - different lower case letters $=p<0.05$.

Table 4

Distribution of uniradicular teeth.

\begin{tabular}{lll}
\hline Group & Anterior & Premolar \\
\hline 1-visit-treatment & $8 / 12$ & $4 / 12$ \\
2-visit-treatment & $7 / 12$ & $5 / 12$ \\
Total & $15 / 24$ & $9 / 24$ \\
\hline
\end{tabular}

two-visit group showed no significant improvement in the reduction of endotoxin levels after the use of $\mathrm{Ca}(\mathrm{OH})_{2}$ medication for 14 days (i.e., reduction from 0.094 to 0.081 ) ( $p>0.05$ ). Thus, the intergroup analysis revealed that the two-visit treatment was more effective in the removal of endotoxins than one-visit treatment $(p<0.05)$ (Table 4).

\section{Discussion}

In the present study, although a significant bacterial load reduction was achieved by using single-file reciprocating instrumentation and irrigation with $2.5 \% \mathrm{NaOCl}$ and $17 \%$ EDTA (from $10^{5}$ to $10^{2} \mathrm{UFC} / \mathrm{mL}$ ), culturable bacteria were still recovered from $50 \%$ of the infected root canals treated in the one-visit group. The limited ability of single-visit treatment on eliminating bacteria from root canal infection has been demonstrated by previous studies in which cultivable bacteria could still be recovered in up to $30-50 \%[6,8,16]$. It is important to highlight that higher success rates of endodontic therapy are reported in teeth with negative bacterial culture $[25,26]$. Thus, the persistence of cultivable bacteria at the time of obturation has shown to reduce such rate $[25,26]$. Considering the limitation of CMP in eliminating bacteria and the search for a supplemental strategy to optimize the root canal disinfection, our clinical study has addressed the supplemental PDT for one-visit and two-visit treatments (Table 5).

PDT is based on the use of photosensitizer activated with low-energy light for production of free-radical species (e.g. singlet oxygen) [27], which is highly reactive and is known to target different bacterial sites, including cell wall, nucleic acid and membrane proteins [28]. All these confer advantages such as broad-spectrum antibacterial activity and low risk of resistance. The effectiveness of PDT depends on different aspects, including photosensitizer and its time of application, light wavelength ( $\mathrm{nm})$, laser type and power $(\mathrm{mW})$, emission laser time [24], type of bacterial infection (whether Gram-positive or Gram-negative), and bacterial growth mode [29].

With regard to the photosensitizer itself, phenothiazines and xanthenes are the two classes commonly tested for antibacterial efficacy $[23,30]$. We have selected the methylene blue (MB), which falls in the category of cationic phenothiazines and is effective against different endodontic bacteria such as Enterococcus ssp. and drug-resistant strains $[23,28,31]$. The high antibacterial effect of MB is attributed to its hydrophilicity, low molecular weight, cationicity [28] and high production of singlet oxygen [30]. Shrestha and Kishen reported that the singlet oxygen production is less impaired by pulp, dentin, and LPSs present in root canals when using MB than other photosensitizer. Particularities of the mechanism of bacterial inactivation by MB are described in the literature [31], which is extensive regarding for phenothiazine dyes [31,32].

Of clinical relevance, our data have demonstrated that the one-visit treatment using single-file reciprocating instrumentation, irrigation (2.5\% $\mathrm{NaOCl}$ and 17\% EDTA) and PDT (application of methyl blue photosensitizer for $60 \mathrm{~s}$ exposed to diode laser at $660 \mathrm{~nm}$ wavelength for $60 \mathrm{~s}$ and potency of $60 \mathrm{~mW}$ for $120 \mathrm{~s}$ ) significantly decreased the levels of bacteria from infected root canals (from 7.01 to $1.16 \times 10^{2} \mathrm{CFU} / \mathrm{mL}$ ). Bonsor et al. [19] using diode laser in similar wavelength $(633 \pm 2 \mathrm{~nm})$, lower laser emission power $(10 \mathrm{~mW})$, longer laser emission time (120 s) and with the application of tolonium chloride photosensitizer for $60 \mathrm{~s}$ significantly enhanced the bacterial load reduction. Typical results are shown by Garcez et al. [20] using diode laser with same wavelength $(660 \mathrm{~nm})$, lower emission power $(40 \mathrm{~mW})$ and 4-time higher laser emission time $(240 \mathrm{~s})$ of conjugate polyethylenimine (PEI) and photosensitizer Chlorin (e6).

In the two-visit group, the use of $\mathrm{Ca}(\mathrm{OH})_{2}$ medication for 14 days significantly improved the reduction of bacterial load and also yielded a higher number of root canals free of cultivable bacteria (3/12) compared to CMP alone by itself (7/12), thus corroborating previous findings $[18,33]$. Particularly, in the two-visit group, the supplemental PDT showed no significant improvement in the median percentage values of bacterial reduction achieved with 14-day application of $\mathrm{Ca}(\mathrm{OH})_{2}$ medication. It agrees with Hidalgo [34], in which a study in dogs

Table 5

Sintomatology of patients.

\begin{tabular}{|c|c|c|c|c|c|c|}
\hline Group & Pain on Percution & Pain on Palpation & Sinus Tract & Exudation & Previous Episode of Pain & Expontaneous Pain \\
\hline 1-visit-treatment & $4 / 12$ & $3 / 12$ & $2 / 12$ & $1 / 12$ & $5 / 12$ & $0 / 12$ \\
\hline 2-visit-treatment & $6 / 12$ & $3 / 12$ & $1 / 12$ & $1 / 12$ & $3 / 12$ & $0 / 12$ \\
\hline Total & $10 / 24$ & $6 / 24$ & $3 / 24$ & $2 / 24$ & $8 / 24$ & $0 / 24$ \\
\hline
\end{tabular}


showed that using aPDT in one-session were worse than those obtained with two session endodontic treatment using a CH-based dressing in teeth with apical periodontitis. In contrast, Garcez et al. [20] performing a weekly treatment using $\mathrm{Ca}(\mathrm{OH})_{2}$ medication and a two session of chemo-mechanical debridement followed by PDT application indicated a significant bacterial load reduction (99.90\%) compared to the first session of treatment after hand instrumentation up to \# 40.02 apical file enlargement. Although our data revealed no significant improvement in bacterial disinfection with supplemental PDT after 14days of $\mathrm{Ca}(\mathrm{OH})_{2}$ medication, a $99.05 \%$ of bacterial reduction was achieved with 14-days of $\mathrm{Ca}(\mathrm{OH})_{2}$ medication, which is close to $99.90 \%$ of disinfection indicated by Garcez et al. [20].

It is important to highlight that there was no significant difference in the bacterial load reduction found after 14 days of $\mathrm{Ca}(\mathrm{OH})_{2}$ medication and after one-visit treatment with supplemental PDT.

To the best of our knowledge, this is the first clinical study evaluating the ability of supplemental PDT to improve the removal of endotoxins from primarily infected root canals after CMP in one-visit and two-visit groups. Gram-negative bacterial endotoxins (LPSs), which exhibit a high biological toxicity and are related to the development of symptoms and severity of bone destruction, were detected in $100 \%$ of the primarily infected teeth in our study agreeing with previous investigations $[8,10,11]$. Our results have revealed that CMP by using single-file reciprocating instrumentation and irrigation with $2.5 \%$ $\mathrm{NaOCl}$ and 17\% EDTA decreased significantly the levels of endotoxin in both one-visit (from 24.941 to $1.920 \mathrm{EU} / \mathrm{mL}$ ) and two-visit (from 25.067 to $1.041 \mathrm{EU} / \mathrm{mL}$ ) groups. Despite such a reduction, the present study has shown the limited ability of CMPs in eliminating endotoxins from primarily infected teeth as endotoxins were recovered from $100 \%$ of the root canals after instrumentation. Such finding is in agreement to previous investigations [8-11].

Additionally, our results revealed not only the ability of $\mathrm{Ca}(\mathrm{OH})_{2}$ (when used as an inter-appointment medication for 14 days) to enhance the reduction of endotoxins levels found in root canal infection (from 1.041 to $0.094 \mathrm{EU} / \mathrm{mL}$ ) but also to eliminate endotoxins from the majority of the root canals $(8 / 12)$. The ability of $\mathrm{Ca}(\mathrm{OH})_{2}$ to neutralize endotoxins in root canals when used as intracanal medication demonstrated in this study is in accordance with previous studies $[6,18]$. The ability of $\mathrm{Ca}(\mathrm{OH})_{2}$ in neutralizing LPS molecule is attributed to its capacity to cleavage ester-linked hydroxy fatty acids [35].

Regardless of the type of treatment (i.e., one-visit or two-visit treatment), the supplemental PDT had no significant effectiveness in reducing the endotoxin levels or in increasing the number of endotoxinfree root canals. Shrestha et al. [30] reported that LPSs decrease the antimicrobial efficacy of PDT. Thus, the higher antimicrobial activity against Gram-positive than Gram-negative bacteria is discussed. Although Gram-positive bacteria possess a porous layer of peptidoglycan and a single lipid layer, Gram-negative bacteria have a double lipid bilayer surrounding the peptidoglycan layer plus an outer layer of lipopolysaccharide, which limits the diffusion of photosensitizer agent into the bacterial cytosol [36] and consequently the antimicrobial activity of PDT.

Finally, the limitations of a clinical study must be taken into consideration. The levels of endotoxins found in root canal infection varied among different patients, and consequently, varied among the groups tested. Thus, although an attempt was made to fill all the canals completely with calcium hydroxide intracanal medication, the completeness of fill and the quantity of intracanal medication in the canals could not be verified.

In conclusion, the photodynamic therapy optimized the disinfection of bacteria from root canals in one-visit but not for two visit treatment modality with the accomplishment of calcium hydroxide medication. Despite the treatment modality, the supplemental PDT was not effective against endotoxins.

\section{References}

[1] R.M. Clarkson, B. Kidd, G.E. Evans, A.J. Moule, The effect of surfactant on the dissolution of porcine pulpal tissue by sodium hypochlorite solutions, J. Endod. 38 (2012) 1257-1260.

[2] M.B. Guneser, D. Arslan, A. Usumer, Tissue dissolution ability of sodium hypochlorite activated by photon-initiated photoacoustic streaming technique, J. Endod. 41 (2015) 729-732.

[3] P.D. Case, P.S. Bird, W.A. Kahler, R. George, L.J. Walsh, Treatment of root canal biofilms of Enterococcus faecalis with ozone gas and passive ultrasound activation, J. Endod. 38 (2012) 523-526.

[4] F.C. Martinho, B.P. Gomes, Quantification of endotoxins and cultivable bacteria in root canal infection before and after chemomechanical preparation with $2.5 \%$ sodium hypochlorite, J. Endod. 34 (2008) 268-272.

[5] F.C. Martinho, W.M. Chiesa, A.C. Marinho, et al., Clinical investigation of the efficacy of chemomechanical preparation with rotary nickel-titanium files for removal of endotoxin from primarily infected root canals, J. Endod. 36 (2010) 1766-1769.

[6] A.C. Xavier, F.C. Martinho, A. Chung, et al., One-visit versus two-visit root canal treatment: effectiveness in the removal of endotoxins and cultivable bacteria, J. Endod. 39 (2013) 959-964.

[7] G.N. Tzanetakis, M.A. Azcarate-Peril, S. Zachaki, et al., Comparison of bacterial community composition of primary and persistent endodontic infections using pyrosequencing, J. Endod. 41 (2015) 1226-1233.

[8] F.C. Martinho, A.P. Gomes, A.M. Fernandes, et al., Clinical comparison of the effectiveness of single-file reciprocating systems and rotary systems for removal of endotoxins and cultivable bacteria from primarily infected root canals, J. Endod. 40 (2014) 625-629.

[9] L. Fabricius, G. Dahlén, S.E. Holm, A.J. Möller, Influence of combinations of oral bacteria on periapical tissues of monkeys, Scand. J. Dent. Res. 90 (1982) 200-206

[10] C.Y. Hong, S.K. Lin, S.H. Kok, et al., The role of lipopolysaccharide in infectious bone resorption of periapical lesion, J. Oral Pathol. Med. 33 (2004) 162-169.

[11] F.G. Cardoso, N.S. Ferreira, F.C. Martinho, et al., Correlation between volume of apical periodontitis determined by cone-beam computed tomography analysis and endotoxin levels found in primary root canal infection, J. Endod. 41 (2015) 1015-1019.

[12] B. Schein, H. Schilder, Endotoxin content in endodontically involved teeth, J. Endod. 32 (4) (2006) 293-295.

[13] N. Horiba, Y. Maekawa, Y. Abe, et al., Correlations between endotoxin and clinical symptoms or radiolucent areas in infected root canals, Oral Surg. Oral Med. Oral Pathol. 71 (1991) 492-495.

[14] F.C. Martinho, W.M. Chiesa, A.A. Zaia, et al., Comparison of endotoxin levels in previous studies on primary endodontic infections, J. Endod. 37 (2011) 163-167.

[15] E.L. Sousa, F.C. Martinho, F.R. Leite, G.G. Nascimento, B.P. Gomes, Macrophage cell activation with acute apical abscess contents determined by interleukin-1 Beta and tumor necrosis factor alpha production, J. Endod. 40 (2014) 1752-1757.

[16] M.A. Neves, J.C. Provenzano, I.N. Rôças, J.F. Siqueira Jr., Clinical antibacterial effectiveness of root canal preparation with reciprocating single-instrument or continuously rotating multi-instrument systems, J. Endod. 42 (2016) 25-29.

[17] J. Vera, J.F. Siqueira, D. Ricucci, et al., One-versus two-visit endodontic treatment of teeth with apical periodontitis: a histobacteriologic study, J. Endod. 38 (2012) 1040-1052.

[18] N.S. Ferreira, F.C. Martinho, F.G. Cardoso, et al., Microbiological profile resistant to different intracanal medications in primary endodontic infections, J. Endod. 41 (2015) 824-830.

[19] S.J. Bonsor, R. Nichol, T.M. Reid, et al., An alternative regimen for root canal disinfection, Br. Dent. J. 201 (2006) 101-105.

[20] A.S. Garcez, S.C. Nuñez, M.R. Hamblin, M.S. Ribeiro, Antimicrobial effects of photodynamic therapy on patients with necrotic pulps and periapical lesion, J Endod. 34 (2008) 138-142.

[21] A.S. Garcez, S.C. Nuñez, M.R. Hamblim, H. Suzuki, M.S. Ribeiro, Photodynamic therapy associated with conventional endodontic treatment in patients with antibiotic-resistant microflora: a preliminary report, J. Endod. 36 (2010) 1463-1466.

[22] J.L. Fimple, C.R. Fontana, et al., Photodynamic treatment of endodontic polymicrobial infection in vitro, J. Endod. 34 (2008) 728-734.

[23] N.S. Soukos, P.A. Chen, J.T. Morris, et al., Photodynamic therapy for endodontic disinfection, J. Endod. 32 (2006) 979-984.

[24] V. Chrepa, G.A. Kotsakis, T.C. Pagonis, K.M. Hargreaves, The effect of photodynamic therapy in root canal disinfection: a systematic review, J. Endod. 40 (2014) 891-898.

[25] A. Molander, J. Warfvinge, C. Reit, T. Kvist, Clinical and radiographic evaluation of one- and two-visit endodontic treatment of asymptomatic necrotic teeth with apical periodontitis: a randomized clinical trial, J. Endod. 33 (2007) 1145-1148.

[26] U. Sjögren, D. Figdor, S. Persson, G. Sundqvist, Influence of infection at the time of root filling on the outcome of endodontic treatment of teeth with apical periodontitis, Int. Endod. J. 30 (1997) 297-306.

[27] M.R. Hamblin, T. Hasan, Photodynamic therapy: a new antimicrobial approach to infectious disease, Photo Sci. 3 (2004) 436-450.

[28] S. George, A. Kishen, Augmenting the antibiofilm efficacy of advanced noninvasive light activated disinfection with emulsified oxidizer and oxygen carrier, J. Endod. 34 (2008) 1119-1123.

[29] M.H. Upadya, A. Kishen, Influence of bacterial growth modes on the susceptibility to light-activated disinfection, Int. Endod. J. 43 (2010) 978-987.

[30] A. Shrestha, A. Kishen, The effect of tissue inhibitors on the antibacterial activity of chitosan nanoparticles and photodynamic therapy, J. Endod. 38 (2012) 1275-1278. 
[31] M. Wainwright, D.A. Phoenix, M. Gaskell, B. Marshall, Photobactericidal activity of methylene blue derivatives against vancomycin-resistant Enterococcus spp, J. Antimicrob. Chemother. 44 (1999) 823-825.

[32] J.P. Tardivo, A. Del Giglio, C.S. de Oliveira, et al., Methylene blue in photodynamic therapy: from basic mechanisms to clinical applications, Photodiagn. Photodyn. Ther. 2 (2005) 175-191.

[33] J.F. Siqueira Jr., T. Guimarães-Pinto, I.N. Rôças, Effects of chemomechanical preparation with $2.5 \%$ sodium hypochlorite and intracanal medication with calcium hydroxide on cultivable bacteria in infected root canals, J. Endod. 33 (2007)
$800-805$.

[34] L.R.D.C. Hidalgo, L.A.B. da Silva, P. Nelson-Filho, et al., Comparison between onesession root canal treatment with aPDT and two-session treatment with calcium hydroxide-based antibacterial dressing, in dogs teeth with apical periodontitis, Lasers Med. Sci. 31 (2016) 1481-1491.

[35] K.E. Safavi, F.C. Nichols, Effect of calcium hydroxide on bacterial lipopolysaccharide, J. Endod. 19 (1993) 76-78.

[36] S.K. Sharma, L.Y. Chiang, M.R. Hamblin, Photodynamic therapy with fullerenes in vivo: reality or a dream, Nanomedicine 6 (2011) 1813-1825. 